\title{
Strategies of Energy Efficiency Design in Traditional Kangbaiwan Mansion in China
}

\author{
Xiaoqing Song and Caili Zhang \\ Zhongyuan University of Technology, Zhengzhou, China
}

\begin{abstract}
The building sector is one of the highest energy consuming sectors in the world as well as in China, it is urgent to seek an energy efficiency way of sustainable architecture development. From the perspective of tradition, this paper focus on strategies of energy efficiency design that contained in excellent vernacular dwellings. On the basis of analyzing an example of Kangbaiwan Mansion, it illustrates the advantage of environment ecosystem, and summarizes the physical and cultural characteristic of its buildings, especially the climate-adapting overall arrangement and sustainable strategies of natural ventilation and passive solar gain, which can be a fertile source of modern energy efficiency architecture design as well as a proper way of inheriting the outstanding traditional culture.
\end{abstract}

\section{Introduction}

Facing to the environmental issues such as accumulating energy crisis and climate change in recent decades, which are not the only ecological concern that should on our list, it is becoming crucial and an inevitable option for sustainable development. Sustainability obtained attention from all walks of life, including building field.

Sustainable architecture in the past thirty years has experienced vigorous development, emerged in a number of important theories and research results. One of them is ecological architecture, which focus on the concept of man's bioclimatic approach and alternative energy strategy. Another is energy-efficient building which concentrates more on the appropriate technique adopted to lower the relative consumption of energy [1]. The further developed concept is defined as green building: The practice of increasing the efficiency with which buildings and their sites use energy, water, and materials, and reducing building impacts on human health and the environment, through better siting, design, construction, operation, maintenance, and removal--the complete building life cycle [2]. In the process, advanced new technology was adopted in the form of all kinds of equipment and installation. Energy efficiency and green building are equivalent to high technology, which has misguided many architecture designs. The comparison of energy-saving design became the competition of higher technology, regardless of the essence of saving.

With the deepening of cognition, architectural experts finally fixed their attention upon sustaining the compatibility of architecture, human beings and the nature, which was named passive design when related to the specific design strategy. Passive design is mentioned much more frequently to the solar usage aspect, which means some designed architectural elements that help gain more solar heating in winter and prevent from overheating in summer, by contrast with active electric solar gain systems.

The broader understanding of passive architecture design can be described as a cost-efficient way of coordinating relationship between artificial structures and the natural environment, which we found some of the principles just existed in the traditional architecture. It is no surprise when the essential of architecture is concerned. From its very beginning, the characteristic of architecture form has been closely related to the specific climate and topography in a certain location. That is the most basic principle appropriate not only in the ancient times but also in modern times. There are also many other strategies deserve review our vision of historical and traditional architecture, which should become a rich source for the creative design of sustainable architecture. "This was not done by the blind imitation and copy of its appearance, but through the conscious and deep understanding of esoteric principles of architecture." [3].

Taking a case study of China as an example, this article discusses the strategies of energy efficiency design in traditional architecture which can be the inspiration for modern sustainable architecture design.

\section{The Kangbaiwan mansion in Gongyi city, Henan province of China}

The Kangbaiwan (a millionaire with the last name Kang) Mansion was first established in the late Ming Dynasty (AD1368 1644) and maintained till the early part of the twentieth century over a period of more than 300 years. At its peak, the relatively self-sufficient estate covered an area of $240 \mathrm{mu}(1 \mathrm{mu}=0.0667$ hectares $)$ and included not only a walled compound for the immediate family and nearby residences for other kin as well as retainers, but also 
ancestral worship facilities, workshop areas, inns for travelers, stables for riding, pack, and work animals, livestock pens, a brick and tile-making kiln, a military camp, and a granary and stores complex [4]. Nowadays, with the traces of most of the ancillary structures, only the main parts of the mansions such as the walled terrace area exist and is an officially protected site in China.

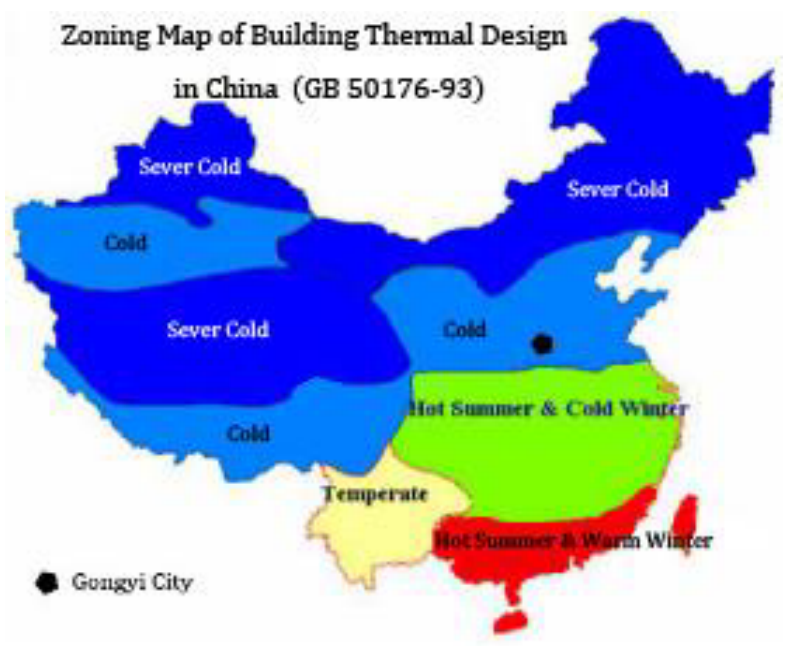

Figure 1. Zoning map of building thermal design in China.

\subsection{Geographic location and climate}

The Kangbaiwan Mansion sits on the terminal of the Loess Plateau, along the Yiluo river, where there is the Yellow river and Mount Mangshan in the North and the Mount Songshan in the south. It's an advantaged geographical position. As a sentry, the Gongyi city next to the ancient capital-Luoyang. So, Gongyi(with the name Gongxian in the history) is the center of wars and a place with economic prosperity from the ancient times. The longitude of the city is $34^{\circ} 31^{\prime} \sim 34^{\circ} 52^{\prime}$ North, its latitude is $112^{\circ} 49^{\prime} \sim 113^{\circ} 17^{\prime}$ East.

Gongyi has a temperate and monsoonal climate with four clearly distinct seasons. It is cold in winter and hot in summer. The average annual temperature is $15.1^{\circ} \mathrm{C}$, About 220 days in the year are frost-free. With the annual mean rainfall is 585 millimeters, the climate is dry (Fig. 1) [5].

\subsection{The environment-adapting arrangement}

From ancient times people have reacted to the natural environment and created a built space not only to provide protection from the vagaries of the weather but to express an understanding of the world [6]. The concept of "fronting water and with hills on the back" is one of the fundamental principles of the ideal environmental pattern for residential area in the architecture tradition of China. This is a true portrayal of Kangbaiwan Mansion's environment. Clinging to the southern slope of Mangshan mountain, The main dwelling houses of the Mansions follow the lie of steep cliff and make the main orientation facing South and East, which is the best orientation to gain more passive solar heating. All the buildings situated on a loessic terrace which is 83 meters from north to south, 73 meters wide and $12 \mathrm{~m} \sim 15 \mathrm{~m}$ high from the ground. The ramp in the arched tunnel is the only access to the terrace which is surfaced by bricks. This ingenious measure provides a safeguard against both natural disaster such as flooding and invaders in troubled times (Fig. 2).

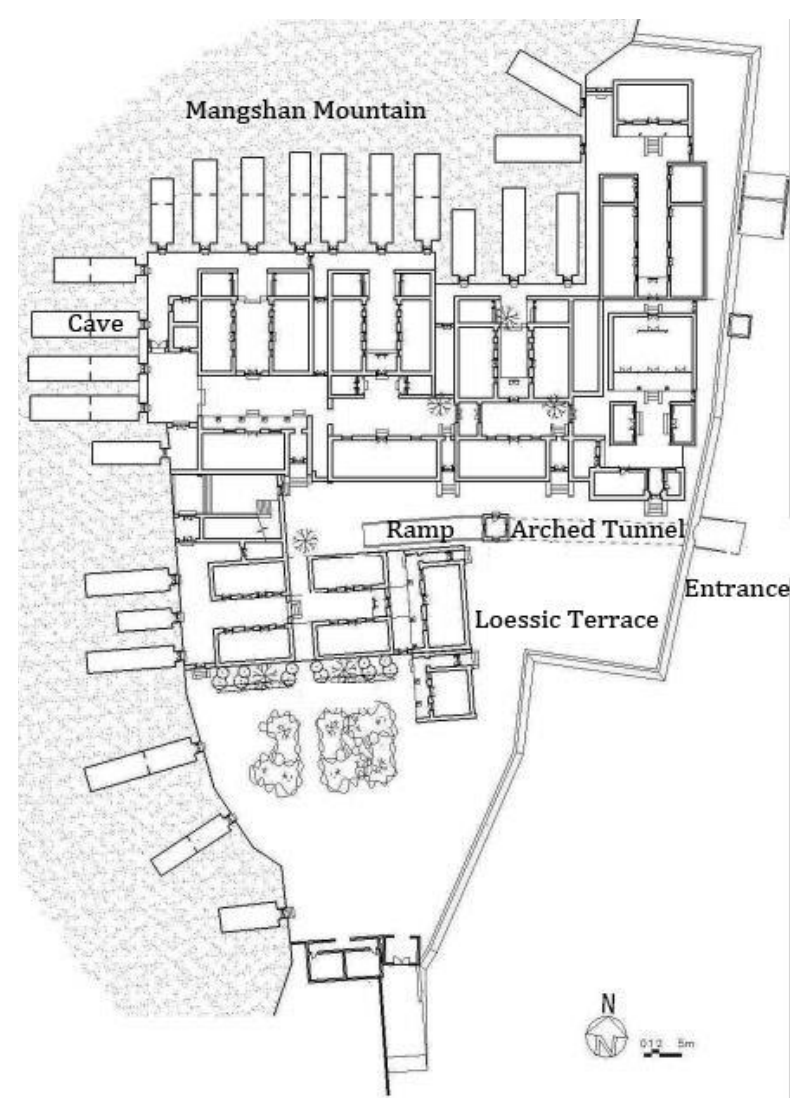

Figure 2. Plan of the main residential area of Kangbaiwan mansion.

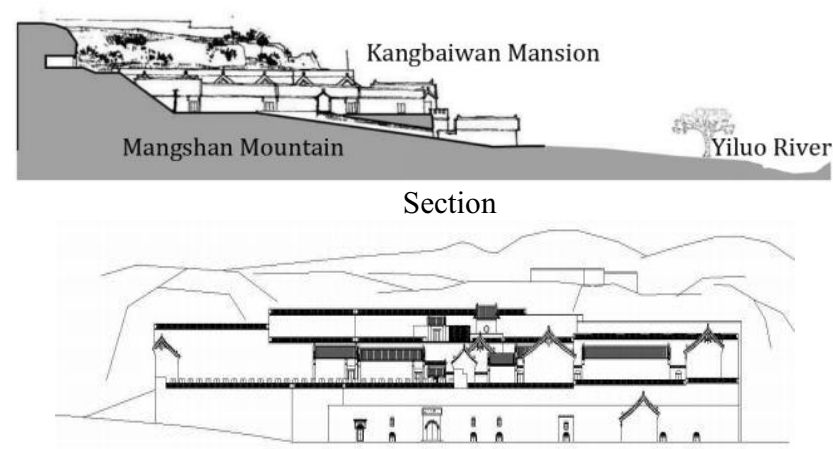

Façade

Figure 3. Environmental Sketch drawing of the main residential area of Kangbaiwan mansion.

To the east of the mansions, the Yiluo river flows pass from southwest to northeast joining into Yellow River about 15 kilometers away. Such geomatic and treasured site offers the residence area to against the chill wind from northwest in winter and guarantee adequate ventilation in summer due to the specific terrain of China which is high in west and low in east. It meets the concept of "harmony between man and nature" of the Oriental philosophy, as well as the spirits of sustainability in modern times (Fig. 3).

When it comes that there is no river available nearby, an alternative solution is a dug pool to fulfill the requirement of water supply for living and fire protection. As the style of 
life changed, the standards of treasured ideal environment for dwelling gradually turn from a physical environment-judge practice to a psychological understanding of living space.

\subsection{The courtyard}

The courtyard is the fundamental unit of architectural complex in China. According to the geographic latitude, the size of yards vary very much. In general, they are wide to obtain enough solar radiation in the high latitude area and narrow to provide more shading in the low latitude area.

As for the Kangbaiwan mansion, Most of Caves were dug as the space of main hall, which form a rectangular courtyard with conventional timber framed, slope roof buildings in other three sides (Fig. 4).

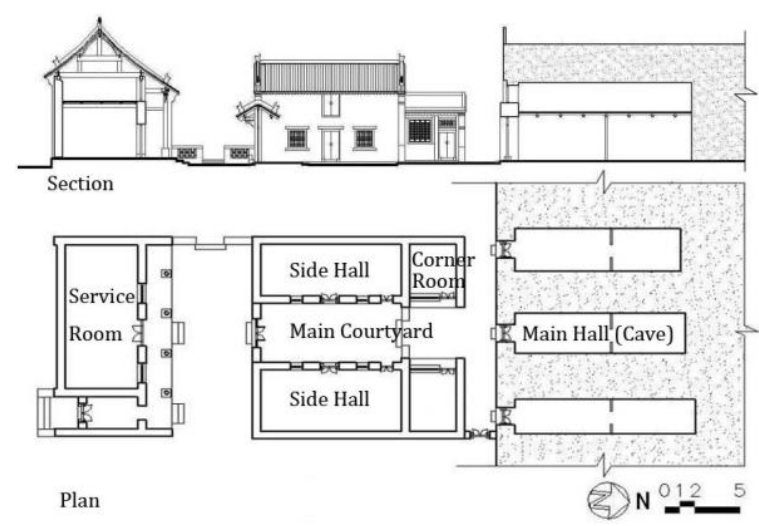

Figure 4. Typical courtyard unit of Kangbaiwan mansion.

With all the doors and windows face the courtyard, it becomes the central area of domesticity. Due to the latitude and mountainous topography of western part of Henan province, the mansion courtyards which only the central bay of the main hall can be seen from the bottom, is relatively narrow compared with the courtyard in the southern of the province which the whole facade of the main hall can be seen (Fig. 5) [7]. Based on the sunlight distribution analysis, it is easy to conclude that the scale of the narrow courtyard fulfill the basic request of solar heating, which was adopted merely followed the good tradition and builders' rich experience.

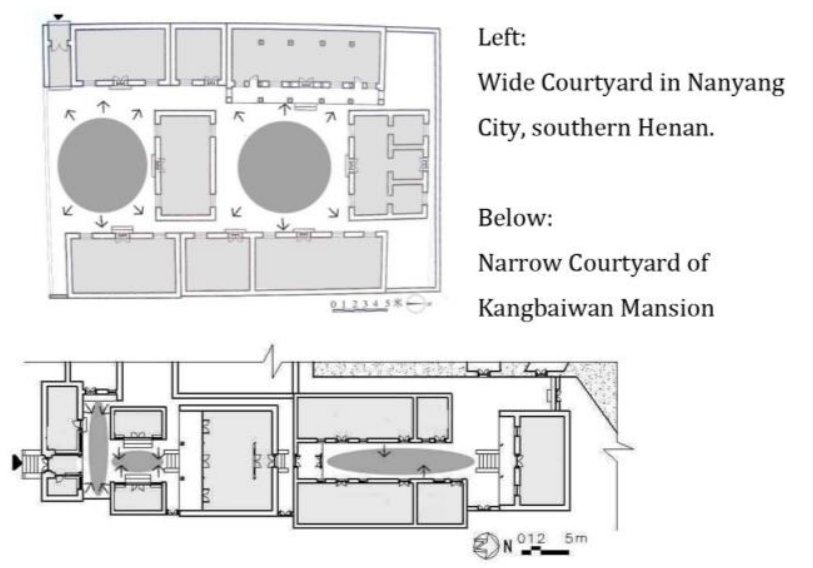

Figure 5. Comparation of two type of courtyard.
Other than that, the trees and flowers planted in yards offer not only a beautiful scenery but also a necessary shading in summer.

Such two or three courtyards range in line forming a central south-north axis which is an ordinary pattern of layout of chinese tradition architecture. The more living spaces are needed, the more such axial group of buildings are built. Most of yards conform with the regulation in Kangbanwan Mansion, while a few form an east-west axis due to the lie of cliff.

\subsection{Strategies of energy saving in architecture}

Many kinds of traditional rural buildings which came into existence after a long time of evolvement can adapt to the local climate and can achieve satisfying thermal comfort.

One of the most significant architectural character of Kangbaiwan mansion is the various architecture typologies that can be arranged in three classes as follows: the cliffside cave dwellings, simulated subterranean structures, and traditional post-beam structures.

Taking advantage of the special geological conditions and climate characteristics, cave-dwellings become the optimal choice for the residence living in the loess plateau area. They are relatively warm in the winter and cool in the summer, as well as cost-efficient and land-saving. The soil has been the main building material for thousands of years due to its great support force and the rainless climate. The arch structure gives full play to such local material and contributes much to cave dwelling. To give more support to the structure, both the facade and interior surface are laid by gray bricks.

The defects of cave-dwellings are the poor lighting and ventilation conditions. The significant feather of cliffside caves in the mansion is that they are two storeys. In addition, there is even a three-storey cave, which is the only one that has been known. Though the space of the second or third floor serve just as storages, the natural lighting and ventilation are improved because of the additional windows and the higher interior space (Fig. 6). The lime mortar painted on the interior surface makes the room bright and absorb humidity as well.

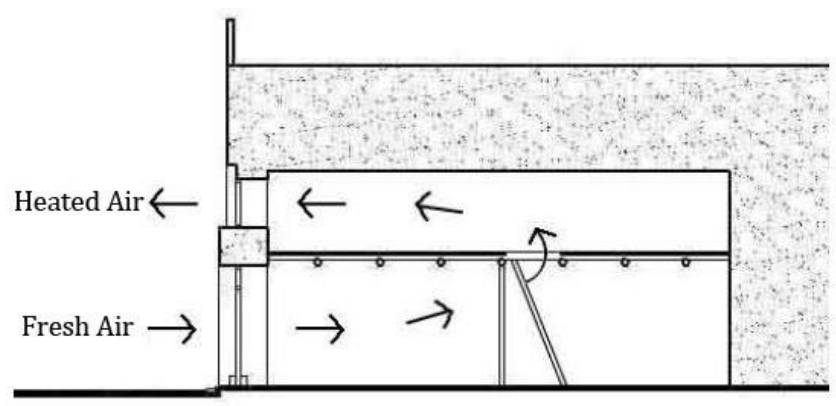

Figure 6. Ventilation analysis of two-storey Cave dwelling in Kangbaiwan mansion.

Such merits are inherited and developed in new type of cave-dwellings, which are performing well both in thermal conditions and energy saving (Fig. 7) [8]. Split-level space is designed to gain more sunlight in the room and increase the 
natural ventilation. In addition, an air exchange fan is installed to refresh the interior space. The creative element is a sunroom in front of the facade, which is integrated for solar heating, thermal insulation, ventilation and cooling.

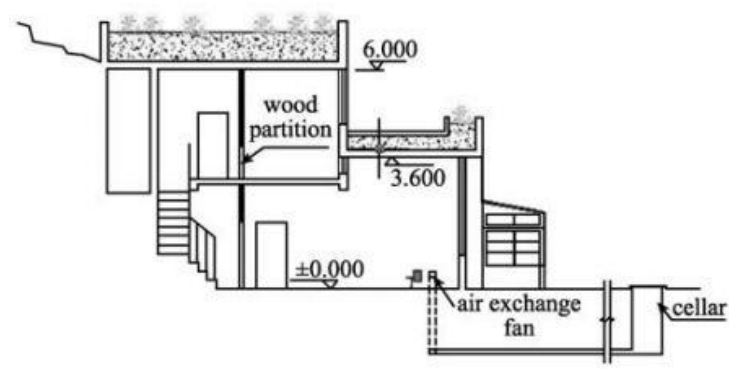

Figure 7. A new type of cave dwelling in Yan'an ,Shaanxi Province.

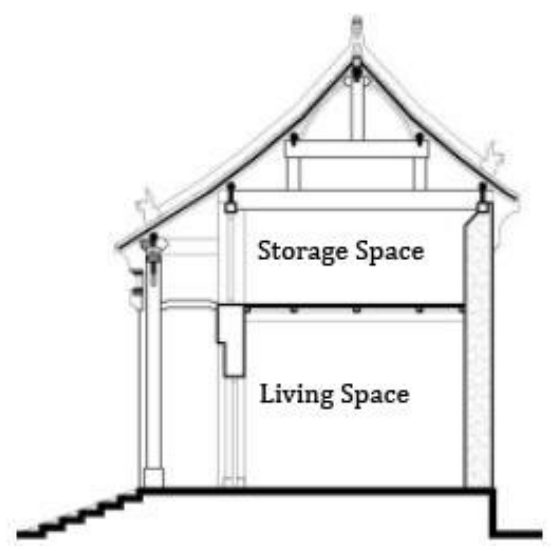

Figure 8. Storage space in the pitched roof building.

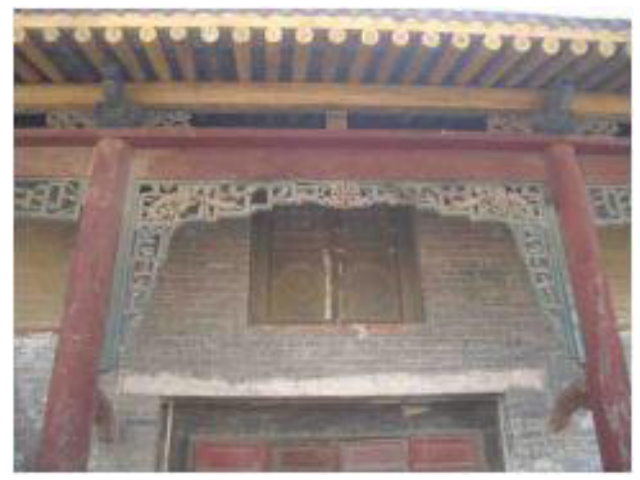

Figure 9. Walls meet the roof truss with some narrow gaps.

The same two-storey strategy was adopted in the traditional post-beam timber architectures in Kangbaiwan Mansion. The storage space under the Pitched roof not only increases the usable area but also improves the insulation performance as a transition area (Fig. 8). The porch in front of the main facade functions as a horizontal transition space mostly in the way of residents' daily activities. It serves as the signal between interior and exterior. Under the roof of the porch, walls meet the roof truss with some narrow gaps by which natural ventilation is promoted, so that the wooden frame can be prevent from decay (Fig. 9). For the main living space, chinese-feathered furnitures also play an important role in the interior comfort. Though designed more likely for privacy, for example, the elaborate alcove bed is an additional compensation of thermal comfort (Fig. 10) [9].

Simulated subterranean structures are created to continue the benefits of caves in the area without available loess cliffs. Just as the name, they simulated the cliffside cave-dwellings by constructing the arch-roof structures and covering with soil, which can also be interpreted as a way of inheriting the local customs and developing regional distinctive features. There are more simulated subterranean buildings than the cliffside cave dwellings in Kangbaiwan mansion because of flexibility.

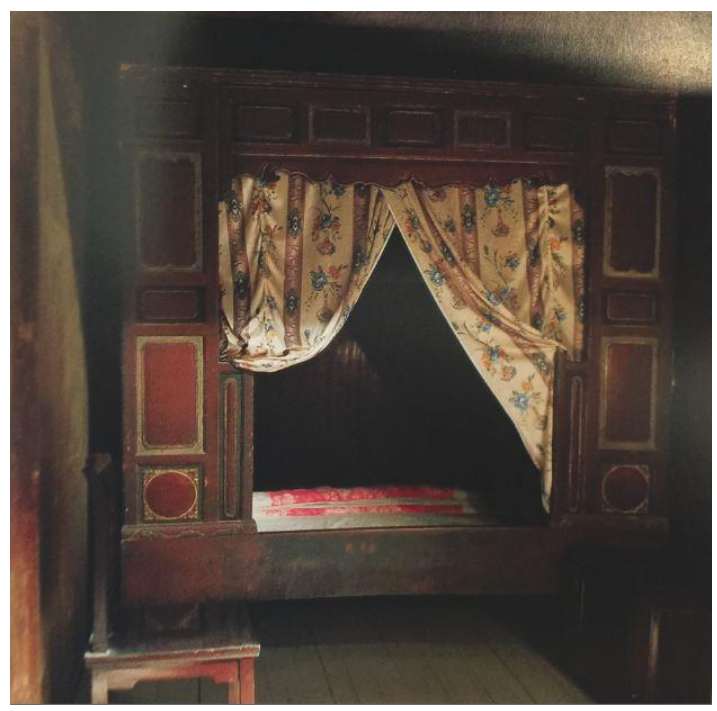

Figure 10. Elaborate alcove bed in Kangbaiwan mansion.

\section{Conclusion}

Before high-tech devices are installed, Strategies of passive building design must be carefully examined and given precedence to act, then twice as much can be accomplished with half the effort. To be part of the movement to seek sustainable development to our troubled earth, many things can be do in the field of energy saving architecture. Looking back into the past, historic and traditional architectures become a fertile source of new sustainable ideas. The proper situation and layout related to a certain geographic location and climate, best orientation and windows arrangement related to effective way of obtaining natural lights and ventilation, various types of space designed to comfort the living space, all of above are the root aspects of energy efficiency design, which our designer should put into practice. Only these basic principles are adopted, shall the subsequent mechanical installation are meaningful.

From the discuss of the example of Kangbaiwan mansion, the key passive design aspects can be summarized as follows:

1) The layout of the site plan is corresponding with the certain geographical environment in the first place.

2) The scale of the narrow courtyards strike a good balance between fulfilling the basic request of solar heating and limited mountainous building site. 
3) The architecture typology of cave dwellings and the second-floor storage spaces are climatic adaptable, energy saving and a good strategy to improve the interior comfort of the main living spaces.

4) Adjusting measures to local conditions, such as local materials and techniques, is the effective way to save the construction cost as well as inherit the local culture.

5) Trees are planted to provide seasoning shading and better the microclimate.

\section{Acknowledgment}

This work was supported by a grant from China Scholarship Council.

\section{References}

1. Yehao Song, The Overview of Development of ecological architectural theories in the West, Word architecture, 1, 67-71 (1998)

2. Sam Kubba, Handbook of Green Building Design, and Construction, LEED, BREEAM, and Green Globes, Butterworth-Heinemann, Oxford (2012)
3. Javad Samadi, Utilizing the Central Courtyard of Traditional Architecture in Modern Architecture, Research Journal of Environmental and Earth Sciences. 6, 3 (2014)

4. Ronald G.Knapp, Chinese Houses:The Architectural Heritage of a Nation, Tuttle publishing, Hong Kong, $146,(2005)$

5. Drawn according to image from: http://aq.zhulong.com/info_wiki/read609337.html

6. Nalanie Mithraratne, Brenda Vale, Robert Vale, Sustainable Living: the Role of Whole Life Costs and Values, Elsevier Limited, Oxford, 4 (2007)

7. Manchang Zuo, Xianchen Bai, Vernacular dwellings in Henan province, China Building Industry Press, Beijin, 165 (2007).

8. Jiaping Liu, Xinrong Zhu, Liu Yang, Rongrong Hu, Exemplary project of green cave dwellings in Loess Plateau, Frontiers of Energy and Power Engineering in China, March, 4, 1 (2010)

9. Ronald G.Knapp, Chinese Houses:The Architectural Heritage of a Nation, Tuttle publishing, Hong Kong, $151(2005)$ 